\title{
24. CAUSES OF COMPRESSIONAL-WAVE ANISOTROPY IN CALCAREOUS SEDIMENTS FROM THE RIO GRANDE RISE ${ }^{1}$
}

\author{
R. L. Carlson, C. H. Schaftenaar, and R. P. Moore, Department of Geophysics and Geodynamics Research Program, \\ Texas A\&M University, College Station, Texas
}

\begin{abstract}
Forty indurated sediment samples from Site 516 were studied to determine the cause of acoustic anisotropy in carbonate-bearing deep-sea sediments. Recovered from sub-bottom depths between 388 and $1222 \mathrm{~m}$, the samples have properties exhibiting the following ranges: wet-bulk density, $1.90-2.49 \mathrm{~g} / \mathrm{cm}^{3}$; fractional porosity, $0.45-0.14$; carbonate content, 33-88\%; compressional-wave velocity (at 0.1 kbar pressure), $1.87-4.87 \mathrm{~km} / \mathrm{s}$; and anisotropy, $1-13 \%$. Velocities were measured in three mutually perpendicular directions through the same specimen in 29 of the 40 samples studied. Calcite fabric has been estimated by X-ray pole figure goniometry. The major findings of this study are:

1) Carbonate-bearing deep-sea sediments may be regarded as transversely isotropic media with symmetry axes normal to bedding.

2) Calcite $c$-axes are weakly concentrated in a direction perpendicular to bedding, but the preferred orientation of calcite does not contribute significantly to velocity anisotropy.

3) The properties of bedded and unbedded samples are distinctly different. Unbedded sediments exhibit low degrees of acoustic anisotropy (1-5\%). By contrast, bedded samples show higher degrees of anisotropy (to $13 \%$ ), and anisotropy increases markedly with depth of burial. Thus, bedding must be regarded as the principal cause of acoustic anisotropy in calcareous, deep-sea sediments.
\end{abstract}

\section{INTRODUCTION}

A principal objective in conducting laboratory studies of the seismic properties of rocks is the refinement of interpretations of seismic refraction and reflection data. "Geoacoustic"' models of the seafloor attempt to relate physical properties of deep-sea sediments to lithology (composition), depth of burial, and diagenetic effects (Hamilton, 1980; Milholland et al., 1980). The occurrence of velocity anisotropy in indurated deep-sea sediments is an important aspect of the problem because of its potential influence on sound transmission in the sediment column (Carlson and Christensen, 1979; Bachman, 1979; Milholland et al., 1980).

Numerous laboratory investigations have established that seismic anisotropy is characteristic of deep-sea sediments (e.g., Boyce, 1976; Tucholke et al., 1976; Carlson and Christensen, 1979; Carlson, 1981, 1982; Carlson et al., 1980). In general, compressional-wave velocities are higher for propagation in the bedding plane than for propagation normal to bedding. Horizontal velocities $\left(V_{h}\right)$ frequently exceed vertical velocities $\left(V_{v}\right)$ by $0.1-0.3$ $\mathrm{km} / \mathrm{s}$, and the range of anisotropy is commonly $0-10 \%$, though higher values have been reported (e.g., Carlson and Christensen, 1979).

Although it is well established that these sediments can be markedly anisotropic, the cause has not been identified. Potential causes of elastic anisotropy in rocks are: (1) alignment of cracks or pores, (2) preferred orientation of anisotropic mineral grains, and (3) compositional layering. This paper constitutes a preliminary re-

\footnotetext{
${ }^{1}$ Barker, P. F., Carlson, R. L., Johnson, D. A., et al. Init. Repts. DSDP, 72: Washington (U.S. Govt. Printing Office).
}

port on the causes of acoustic anisotropy in indurated calcareous sediments recovered at DSDP Hole $516 \mathrm{~F}$ on the Rio Grande Rise.

\section{PROCEDURES}

Hole $516 \mathrm{~F}$ was drilled to a sub-bottom depth of $1270.6 \mathrm{~m}$ and penetrated basaltic basement at $1250 \mathrm{~m}$. Forty samples for this study were collected from the interval below $300 \mathrm{~m}$. Wet-bulk densities were estimated on ship by the 2-minute GRAPE method as described by Boyce (1976), and the samples were carefully packaged to maintain water saturation during shipment to the shore laboratory.

The samples used for density and acoustic velocity measurements are cubes $2.00 \pm 0.01 \mathrm{~cm}$ on a side. Wet-bulk densities were calculated from the weights and dimensions of the cubes and are accurate to $\pm 1 \%$. Water contents of selected samples were determined separately, and porosities calculated from measured densities and water contents are accurate to $\pm 0.01-0.03$ (fractional porosity units).

The degree of water saturation is a critically important factor affecting the acoustic properties of rocks (Wyllie et al., 1958). Two lines of evidence suggest that the samples remained saturated during shipment and storage. Densities determined on ship agree with the shore laboratory densities within approximately $1 \%$, suggesting that no significant amount of water was lost from the samples. Further, a plot of porosity versus wet-bulk density (Fig. 1) shows the expected strong linear trend with little scatter. Mean grain and pore-fluid densities estimated by linear regression are $2.71 \pm 0.01$ and $1.00 \pm 0.04 \mathrm{~g} / \mathrm{cm}^{3}$, respectively. Both of these values are within acceptable limits for a suite of brine-saturated deep-sea sediments.

Carlson (1981) has pointed out that when horizontal and vertical velocities are measured through different samples, the true degree of velocity anisotropy is often difficult to determine because the elastic properties are affected by differences in bulk density. To overcome this difficulty, a cast-urethan sample holder with a cubic sample volume and cylindrical electrode ports was devised, so that acoustic-wave velocities could be measured in three mutually perpendicular directions through the same sample at elevated confining pressures. Details of the design will be described in a subsequent publication. $1-\mathrm{MHz}$ PZT-5 transducers were used to measure acoustic velocities by the pulse transmission method, at hydrostatic confining pressures to 0.3 or $0.6 \mathrm{kbar}$. The accuracy of the velocity determinations is $\pm 1 \%$. Physical properties data are summarized in Table 1. 


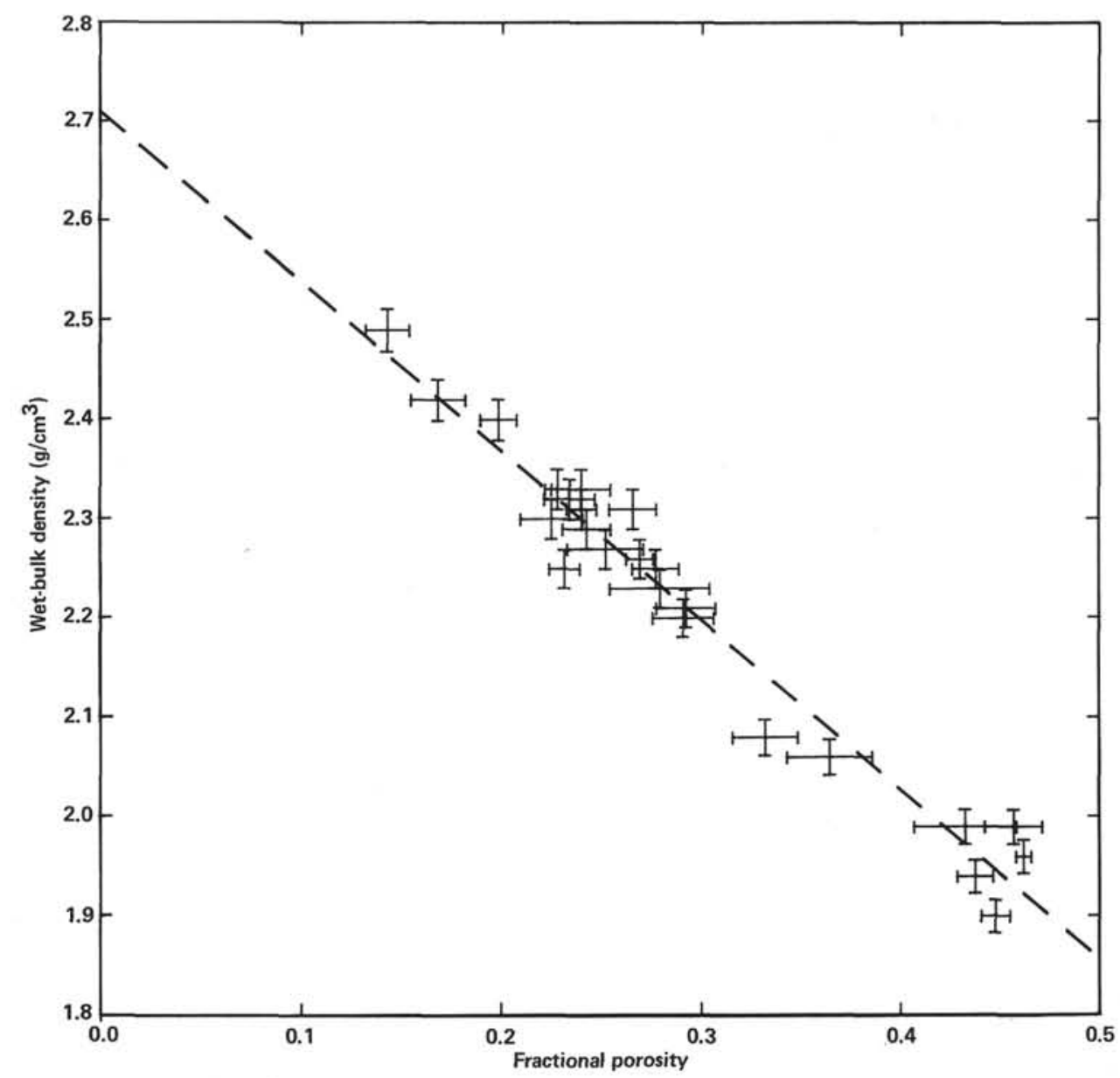

Figure 1. Wet-bulk density versus fractional porosity of 24 selected samples from Site 516 . The dashed line represents a best-fitting relation of the form $\varrho_{b}=\varrho_{g}-a \phi ; r=-0.98 ; a=-1.71 \pm 0.04$; $\varrho_{\mathrm{g}}=2.71 \pm 0.01$. ( $\varrho_{\mathrm{g}}$ is grain density, $\varrho_{\mathrm{b}}$ is bulk density, $\phi$ is porosity, $\mathrm{a}$ is $\varrho_{\mathrm{f}}-\varrho_{\mathrm{g}}$.)

\section{DATA SUMMARY}

The samples for this study were recovered from subbottom depths between 388 and $1222 \mathrm{~m}$. Although all have a significant carbonate component, not all are chalks: carbonate contents range from 34 to $88 \%$. The principal noncarbonate components are clay minerals, generally smectites. Wet-bulk densities range from 1.9 to $2.5 \mathrm{~g} / \mathrm{cm}^{3}$, and the corresponding range of fractional porosities is $0.46-0.14$. The degree of compressionalwave anisotropy ranges from about $1-13 \%$. The maximum difference between horizontal and vertical velocities is $0.43 \mathrm{~km} / \mathrm{s}$.

The velocity-density relationship for this set of samples is illustrated in Figure 2. Data from Carlson and Christensen (1979) are included for comparison. The results from this study are consistent with the best-fitting velocity-density relation given by Hamilton (1978).

\section{GENERAL REMARKS}

A significant finding is that horizontal velocities generally differ from each other by only a few hundredths of a km/s. This relationship is evident in Figure 2, and is well illustrated by the typical velocity-pressure relation- ships shown in Figure 3. In most cases, the difference between the measured horizontal velocities is less than the expected error of the velocity measurement. Thus, these indurated deep-sea sediments may be regarded as transversely isotropic, with a symmetry axis perpendicular to bedding.

Carlson and Christensen (1979) studied 11 samples from three sites in the western South Atlantic. Their results suggested that velocity anisotropy increases with increasing density and with mean velocity. Figure 2 shows that samples exhibiting the highest degrees of anisotropy have densities in excess of about $2.25 \mathrm{~g} / \mathrm{cm}^{3}$, but it is also evident that anisotropy is highly variable within any chosen density interval. Similarly, a plot of anisotropy versus mean velocity (Fig. 4) shows no strong relationship between these parameters. Apparently, the development of elastic anisotropy in deep-sea sediments is a considerably more complex process than the simple relationships found in the previous study implied.

\section{CAUSES OF ANISOTROPY}

As noted above, possible causes of elastic anisotropy in aggregates are preferred orientation of cracks and pores, preferred orientation of the anisotropic mineral 
Table 1. Summary of physical properties, Hole 516F.

\begin{tabular}{|c|c|c|c|c|c|c|c|c|c|c|}
\hline \multirow{2}{*}{$\begin{array}{c}\text { Core-section } \\
\text { (interval in cm) }\end{array}$} & \multirow{2}{*}{$\begin{array}{l}\text { Sub-bottom } \\
\text { depth } \\
\text { (m) }\end{array}$} & \multirow{2}{*}{$\begin{array}{l}\text { Density } \\
\left(\mathrm{g} / \mathrm{cm}^{3}, \pm 1 \%\right)\end{array}$} & \multirow{2}{*}{$\begin{array}{l}\text { Fractional } \\
\text { porosity }\end{array}$} & \multicolumn{3}{|c|}{$\begin{array}{l}\mathrm{V}_{\mathrm{p}} \text { at } 0.1 \mathrm{kbar} \\
(\mathrm{km} / \mathrm{s}, \pm 1 \%)\end{array}$} & \multirow{2}{*}{$\underset{(\mathrm{km} / \mathrm{s})}{\Delta \mathrm{V}}$} & \multirow{2}{*}{$\begin{array}{l}\text { Anisotropy } \\
(\%, \pm 1.2)\end{array}$} & \multirow{2}{*}{$\begin{array}{c}\text { Carbonate } \\
\text { content } \\
(\%, \pm 2)\end{array}$} & \multirow[b]{2}{*}{ Bedding } \\
\hline & & & & h1 & h2 & $\mathbf{v}$ & & & & \\
\hline $24-1,17-26$ & 388 & 1.90 & $0.45 \pm 0.01$ & 1.96 & & 1.91 & $0.05 \pm 0.02$ & 2.6 & 79 & U \\
\hline $25-3,44-53$ & 401 & 2.01 & $0.41 \pm 0.02^{\mathrm{a}}$ & 1.96 & 1.96 & 1.92 & $0.04 \pm 0.02$ & 2.1 & 68 & B \\
\hline $26-1,17-25$ & 407 & 1.99 & $0.43 \pm 0.03$ & 1.91 & & & & & 65 & B \\
\hline $29-1,41-51$ & 436 & 1.96 & $0.46 \pm 0.01$ & 1.94 & & 1.87 & $0.07 \pm 0.02$ & 3.7 & 81 & B \\
\hline $32-1,15-25$ & 464 & 1.99 & $0.42 \pm 0.02^{\mathrm{a}}$ & 2.07 & 2.07 & 2.00 & $0.07 \pm 0.02$ & 3.4 & 74 & B \\
\hline $34-1,25-35$ & 483 & 1.94 & $0.44 \pm 0.01$ & 2.00 & & 1.96 & $0.04 \pm 0.02$ & 2.0 & 75 & B \\
\hline $41-1,85-93$ & 550 & 2.00 & $0.42 \pm 0.02^{\mathrm{a}}$ & 2.18 & 2.07 & 2.08 & $0.05 \pm 0.03$ & 2.1 & 89 & B \\
\hline $50-1,100-110$ & 636 & 2.06 & $0.36 \pm 0.02$ & 2.54 & 2.58 & 2.47 & $0.09 \pm 0.03$ & 3.6 & 84 & $\mathrm{U}$ \\
\hline $52-3,5-14$ & 658 & 2.04 & $0.39 \pm 0.02^{\mathrm{a}}$ & 2.33 & 2.31 & 2.27 & $0.05 \pm 0.03$ & 2.2 & 74 & U \\
\hline $55-2,43-53$ & 684 & 2.08 & $0.33 \pm 0.02$ & 2.87 & & 2.80 & $0.07 \pm 0.03$ & 2.5 & 70 & $\mathrm{U}$ \\
\hline $58-1,78-88$ & 711 & 2.22 & $0.29 \pm 0.02^{\mathrm{a}}$ & 2.50 & 2.48 & 2.37 & $0.12 \pm 0.03$ & 4.9 & 76 & B \\
\hline $60-4,112-122$ & 726 & 2.21 & $0.29 \pm 0.01$ & 2.52 & & 2.40 & $0.12 \pm 0.03$ & 4.8 & 74 & B \\
\hline $62-2,48-56$ & 740 & 2.25 & $0.27 \pm 0.02^{\mathrm{a}}$ & 2.65 & 2.64 & 2.54 & $0.11 \pm 0.03$ & 4.0 & 72 & B \\
\hline $70-1,22-32$ & 796 & 2.30 & $0.24 \pm 0.02^{\mathrm{a}}$ & 2.93 & 2.95 & 2.74 & $0.20 \pm 0.03$ & 7.0 & 65 & B \\
\hline $75-4,110-120$ & 838 & 2.42 & $0.17 \pm 0.01$ & 3.55 & 3.47 & 3.25 & $0.26 \pm 0.04$ & 7.6 & 72 & B \\
\hline $78-4,1-11$ & 864 & 2.25 & $0.28 \pm 0.01$ & 2.46 & & 2.43 & $0.03 \pm 0.03$ & 1.2 & 64 & $\mathrm{U}$ \\
\hline $79-2,93-103$ & 871 & 2.33 & $0.24 \pm 0.01$ & 2.96 & 2.96 & 2.75 & $0.21 \pm 0.03$ & 7.3 & 65 & B \\
\hline $80-2,32-39$ & 879 & 2.25 & $0.23 \pm 0.01$ & 3.66 & 3.60 & 3.54 & $0.09 \pm 0.04$ & 2.5 & 77 & $\mathrm{U}$ \\
\hline $83-2,70-80$ & 903 & 2.22 & $0.29 \pm 0.02^{\mathrm{a}}$ & 3.11 & 3.09 & 3.08 & $0.02 \pm 0.04$ & 0.6 & 88 & U \\
\hline $84-6,20-30$ & 918 & 2.20 & $0.29 \pm 0.02$ & 3.05 & 3.05 & 2.97 & $0.08 \pm 0.04$ & 2.6 & 82 & $\mathrm{U}$ \\
\hline $85-1,20-30$ & 920 & 2.12 & $0.35 \pm 0.02^{\mathrm{a}}$ & 2.66 & 2.70 & 2.62 & $0.06 \pm 0.03$ & 2.3 & 87 & $\mathrm{U}$ \\
\hline $86-2,44-54$ & 931 & 2.23 & $0.28 \pm 0.03$ & 3.00 & 3.00 & 2.90 & $0.10 \pm 0.04$ & 3.4 & 83 & U \\
\hline $87-5,112-121$ & 946 & 2.27 & $0.26 \pm 0.02^{\mathrm{a}}$ & 3.03 & 3.07 & 3.00 & $0.05 \pm 0.04$ & 1.6 & 85 & U \\
\hline $90-3,123-132$ & 971 & 2.15 & $0.33 \pm 0.02^{\mathrm{a}}$ & 2.72 & 2.74 & 2.68 & $0.05 \pm 0.03$ & 1.8 & 81 & U \\
\hline $91-5,78-87$ & 983 & 2.27 & $0.25 \pm 0.02$ & 3.16 & & 3.10 & $0.06 \pm 0.04$ & 1.9 & 82 & U \\
\hline $93-4,126-135$ & 1001 & 2.29 & $0.25 \pm 0.02^{\mathrm{a}}$ & 2.47 & 2.47 & 2.27 & $0.20 \pm 0.03$ & 8.3 & 45 & B \\
\hline $100-3,44-53$ & 1048 & 2.31 & $0.27 \pm 0.01$ & 2.43 & & 2.31 & $0.12 \pm 0.03$ & 5.0 & 48 & U \\
\hline $101-2,95-105$ & 1053 & 2.32 & $0.23 \pm 0.02^{\mathrm{a}}$ & 3.02 & 2.99 & 2.74 & $0.27 \pm 0.03$ & 9.1 & 65 & B \\
\hline $102-2,121-131$ & 1058 & 2.30 & $0.23 \pm 0.02$ & 2.63 & & 2.36 & $0.27 \pm 0.03$ & 10.6 & 52 & B \\
\hline $103-3,30-39$ & 1063 & 2.29 & $0.24 \pm 0.01$ & 2.98 & 3.03 & 2.75 & $0.26 \pm 0.03$ & 8.7 & 65 & B \\
\hline $105-5,0-10$ & 1084 & 2.31 & $0.24 \pm 0.01$ & 3.05 & & 2.79 & $0.26 \pm 0.04$ & 8.8 & 57 & B \\
\hline $106-3,20-30$ & 1090 & 2.26 & $0.27 \pm 0.01$ & 3.09 & 3.06 & 2.87 & $0.21 \pm 0.04$ & 6.8 & 68 & B \\
\hline $107-4,125-134$ & 1101 & 2.33 & $0.22 \pm 0.02^{\mathrm{a}}$ & 3.00 & 3.01 & 2.75 & $0.26 \pm 0.03$ & 8.7 & 55 & B \\
\hline $108-3,114-124$ & 1109 & 2.33 & $0.23 \pm 0.01$ & 3.07 & 3.11 & 2.82 & $0.27 \pm 0.04$ & 9.0 & 59 & B \\
\hline $109-3,107-116$ & 1113 & 2.32 & $0.23 \pm 0.01$ & 3.11 & 3.11 & 2.75 & $0.36 \pm 0.04$ & 12.0 & 63 & B \\
\hline $113-5,78-87$ & 1152 & 2.38 & $0.19 \pm 0.02^{\mathrm{a}}$ & 3.63 & 3.67 & 3.28 & $0.36 \pm 0.04$ & 10.5 & 65 & B \\
\hline $116-2,110-120$ & 1175 & 2.40 & $0.20 \pm 0.01$ & 3.34 & 3.41 & 2.95 & $0.43 \pm 0.04$ & 13.1 & 34 & B \\
\hline $117-4,116-125$ & 1187 & 2.49 & $0.14 \pm 0.01$ & 4.01 & 4.01 & 3.69 & $0.32 \pm 0.05$ & 8.2 & 75 & B \\
\hline $119-3,62-71$ & 1198 & 2.43 & $0.16 \pm 0.02^{\mathrm{a}}$ & 4.18 & 4.19 & 3.95 & $0.24 \pm 0.05$ & 5.7 & 78 & B \\
\hline $122-1,77-86$ & 1222 & 2.48 & $0.14 \pm 0.02^{\mathrm{a}}$ & 4.87 & 4.83 & 4.50 & $0.35 \pm 0.06$ & 7.4 & 51 & B \\
\hline
\end{tabular}

Note: $\mathrm{V}_{\mathrm{p}}=$ compressional-wave velocity; $\mathrm{h} 1=$ horizontal velocity $1 ; \mathrm{h} 2=$ horizontal velocity $2 ; \mathrm{v}=$ vertical velocity; $\mathrm{B}=$ bedded sample; $\mathrm{U}=$ unbedded sample.

a Porosity calculated using regression equation.

grains, and compositional layering (bedding). An important objective of this research has been to determine which of these mechanisms is the principal cause of acoustic anisotropy in deep-sea sediments.

Cracks are rarely observed in thin sections of deepsea sediments but a preferred orientation of elongate pores might cause the sediments to be anisotropic. Carlson and Christensen (1979) pointed out that such pores should close at elevated confining pressures, and that anisotropy would then decrease with pressure. Carlson and Christensen (1979) and Bachman (1979) found that anisotropy is independent of confining pressure and concluded that pore geometry cannot be a principal contributor to the phenomenon. More recently, Kim and others (1982) made velocity measurements under controlled pore pressure conditions and found some tendency for anisotropy to decrease with increasing effective pressure. They also used scanning electron microscopy to examine their samples, found a slight degree of pore alignment parallel to bedding, and concluded that pore geometry does contribute to observed velocity anisotropy. Velocity-pressure relations, however, do not constitute the only line of evidence pertaining to pore geometry as a cause of anisotropy. The degree of anisotropy tends to increase with density and depth of burial, as reported by Carlson and Christensen (1979). The influence of pore alignment on the acoustic properties should decrease with increasing density (decreasing po- rosity). In fact, samples exhibiting the highest degree of velocity anisotropy have bulk densities in excess of $2.25 \mathrm{~g} / \mathrm{cm}^{3}$, as shown in Figure 5. Thus, though the pore geometry may affect the properties of low-density samples, it is an unlikely cause of significant anisotropy in indurated deep-sea carbonates.

A second possible cause of elastic anisotropy in rocks is preferred orientation of anisotropic mineral grains. Preferred orientation of olivine grains, for example, accounts for the anisotropic nature of most ultramafic rocks (Crosson and Lin, 1971; Baker and Carter, 1972). Calcite is a highly anisotropic mineral in which the compressional-wave velocity parallel to the $c$-axis is 5.6 $\mathrm{km} / \mathrm{s}$ and the velocity perpendicular to $c$ is $7.4 \mathrm{~km} / \mathrm{s}$ (e.g., Dandekar, 1968). Carlson and Christensen (1979) pointed out that preferred orientation of calcite with a concentration of $c$-axes normal to bedding would explain the pattern of acoustic anisotropy observed in calcareous sediments. They further noted that certain disclike carbonate nannofossils such as Discoaster, Coccolithus, and Cyclococcolithina have structures in which the $c$-axes of calcite microcrysts are perpendicular to their long dimensions, and they suggested that such forms might be aligned with bedding planes as the sediments are compacted to produce an initial preferred orientation of calcite. Milholland and others (1980) have pointed out that the structure of some foraminifers is such that the alignment of foraminiferal fragments with 


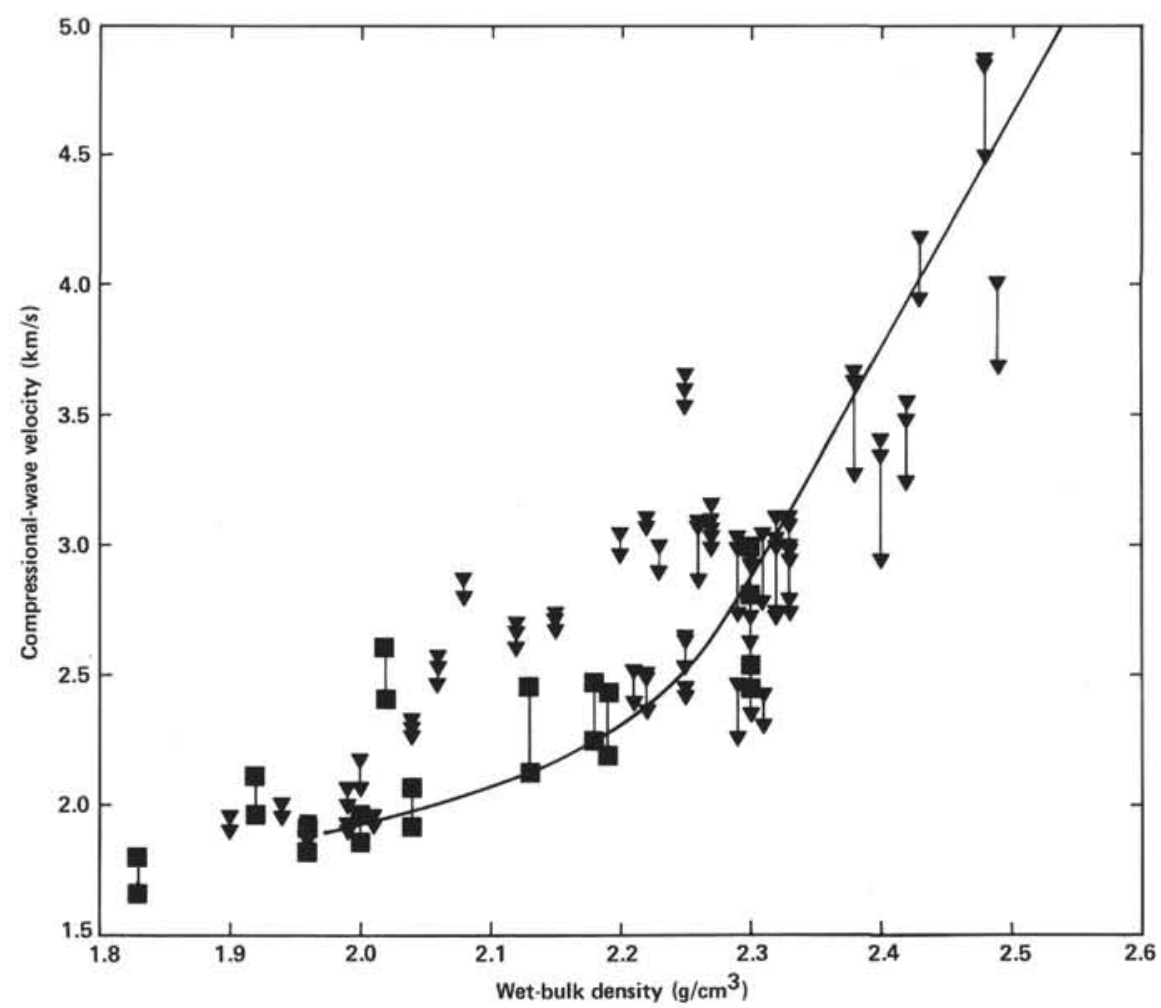

Figure 2. Compressional-wave velocity versus wet-bulk density. Squares indicate 11 samples from the western South Atlantic (Carlson and Christensen, 1979). Inverted triangles indicate Leg 72 samples (this study). Vertical lines connect vertical and horizontal velocities measured through the same sample. Solid line is velocity-density relation given by Hamilton (1978).

bedding would also contribute to the development of a preferred orientation of calcite $c$-axes normal to bedding. To account for the observed increase of anisotropy with depth, Carlson and Christensen (1979) further suggested that initial, compaction-produced fabric might be enhanced by diagenetic processes such as epitaxial growth of suitably oriented grains. This model is conceptually attractive and seemingly reasonable, but it has not been tested by making measurements of the degree of preferred mineral orientation in deep-sea sediment samples.

A question of immediate interest is, what is the maximum degree of velocity anisotropy that can be produced by preferred orientation of calcite in a porous, watersaturated rock? Clearly, the degree of anisotropy will be maximum when the rock consists entirely of calcite, and the calcite $c$-axes are perfectly aligned, so that the rock approximates a porous, water-saturated single crystal. Compressional-wave velocities parallel and perpendicular to the calcite $c$-axes then correspond to $\mathrm{V}_{\mathrm{v}}$ and $\mathrm{V}_{\mathrm{h}}$, and are respectively, 5.6 and $7.4 \mathrm{~km} / \mathrm{s}$ (Dandekar, 1968). The empirical, time-average relation (Wyllie et al., 1956) is commonly used to estimate compressionalwave velocities in porous aggregates. Strictly speaking, the time-average relation applies to isotropic rocks, but by applying it to particular directions of propagation, one can estimate velocities in the $a$ and $c$ directions through a porous single crystal and make a rough calculation of the variation of acoustic anisotropy with po- rosity or density. This approximate relationship is shown in Figure 5 and predicts degrees of anisotropy only slightly higher than those observed. The proximity of the estimated maximum possible values to the measured values suggests that if preferred orientation of calcite is a principal cause of elastic anisotropy in deep-sea sediments, the concentration of $c$-axes normal to bedding must be quite pronounced.

Optical methods that are commonly used to measure grain orientation in coarse-grained rocks cannot be applied to fine-grained aggregates such as deep-sea carbonates, but X-ray pole figure goniometry, as described, for example, by Baker and others (1969), lends itself to this problem. The technique is based on the fact that the intensity of a particular Bragg diffraction peak is proportional to the concentration of suitably oriented diffracting planes in the target. Thus, by setting the primary beam and detector for a particular plane in the mineral being studied and rotating the specimen, one can map the degree of preferred orientation of that particular plane. Because the various diffracting planes are symmetrically related, the arrangement of mineral grains in the sample, or "crystallite orientation distribution function", can be completely characterized if the distributions of a number of diffracting planes are known (Roe and Krigbaum, 1964). We have used X-ray pole figure goniometry to measure the preferred orientation of calcite in a number of samples from Hole 516F. In this report, we use the data from a typical sample to 

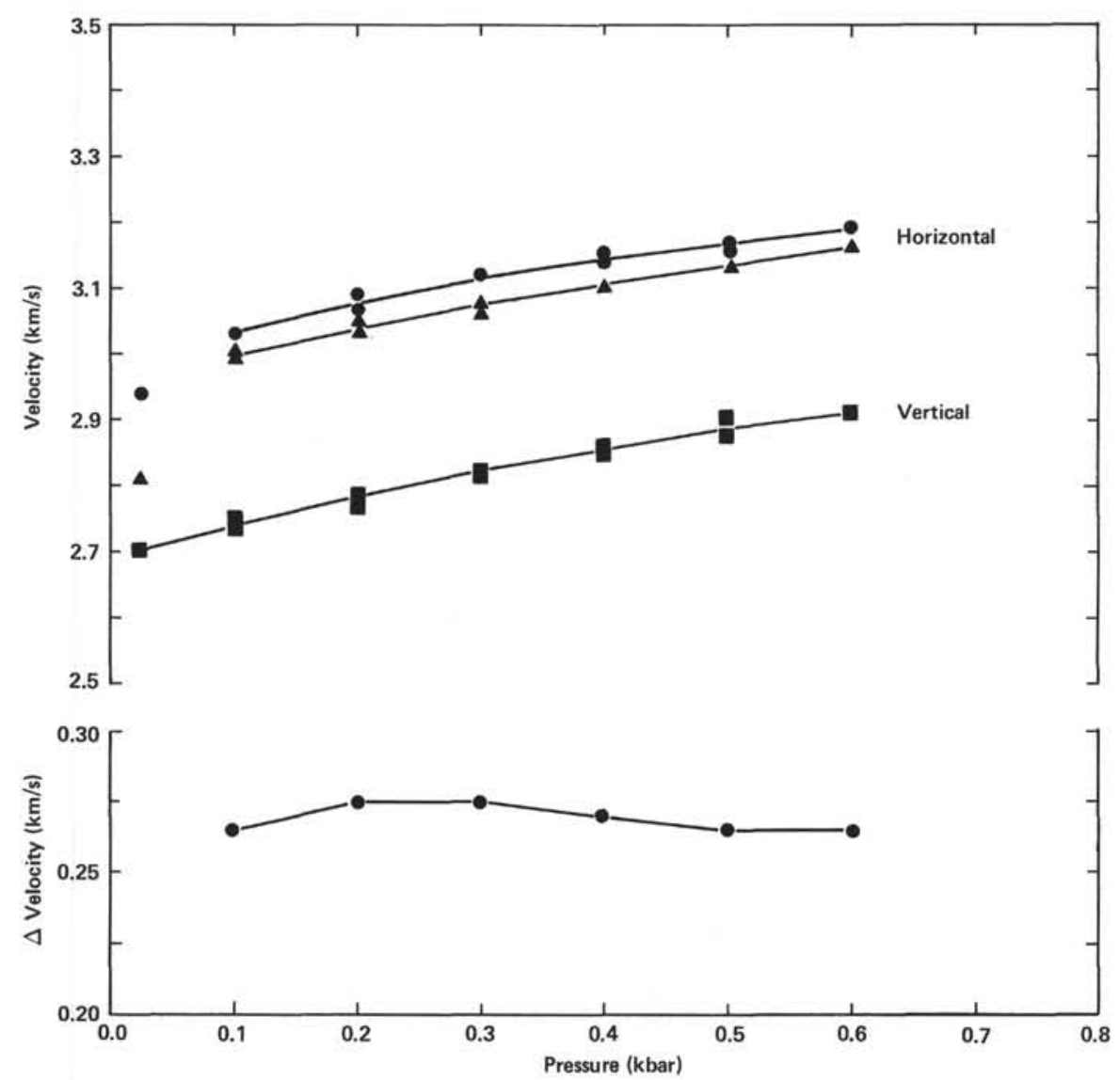

Figure 3. Typical relationships between pressure and velocity and velocity difference $(\Delta \mathrm{V}$ is the difference between vertical and horizontal velocities). Sample $516 \mathrm{~F}-101-2,95-105 \mathrm{~cm}$; density $=2.32 \mathrm{~g} / \mathrm{cm}^{3}$.

illustrate and summarize our results. We will present a more detailed description of the method, results, and implications at a later date (Schaftenaar and Carlson, in preparation).

A major difficulty encountered in the application of the X-ray method to deep-sea carbonates results from the fact that the intensity of the diffracted beam is sensitive to changes in the composition of the area illuminated by the primary beam. Because of small-scale variations in composition related to bedding, a complete determination of the calcite distribution function for deep-sea carbonates cannot be made with confidence; the effects of compositional variation cannot be separated from the effects of preferred orientation in the $\mathrm{X}$-ray data. However, if the orientation distribution is symmetric about an axis of known orientation, this difficulty can be largely overcome. The approximately symmetric structures of calcareous nannofossils, the compaction model proposed by Carlson and Christensen (1979) and Milholland and others (1980) and the fact that the samples exhibit transverse isotropy all suggest that the distribution of calcite $c$-axes is symmetrical about an axis normal to bedding. Under these circumstances, the orientation distribution for a specified plane can be determined by measuring the diffracted-beam intensity as a function of the angle between the normal to bedding and the normal to suitably oriented diffraction planes-that is, by recording the intensity as the sample is rotated about an axis lying in the bedding plane.

Diffractions from planes normal to the calcite $c$-axis [0001] are so weak that they cannot be used to measure the preferred orientation of $c$ directly. Instead, the measured distributions of [10 $\overline{1} 1]$ ( $r$ plane), [11 $\overline{2} 0]$ ( $a$ axis),

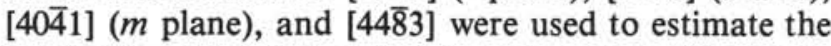
crystallite orientation distribution by spherical harmonic analysis (Roe and Krigbaum, 1964; Baker et al., 1969). The $c$-axis distribution was then calculated from the orientation distribution function.

A typical result is shown in Figure 6 for Sample $516 \mathrm{~F}-86-2,44-54 \mathrm{~cm}$. The measured anisotropy is $3.4 \%$, and the difference between the horizontal and vertical velocities is $0.1 \pm 0.04 \mathrm{~km} / \mathrm{s}$. The normalized $r$ and $a$ distributions are shown in Figures $6 \mathrm{~A}$ and $\mathrm{B}$, respectively. Only the first two coefficients of the best-fitting Legendre Polynomial series are well constrained in each case. These coefficients were used to find the coefficients of the associated Legendre Polynomial series (crystallite orientation distribution function), from which the $r, a$, and $c$ distributions shown in Figure $6 \mathrm{C}$ were calculated. The preferred orientation of calcite with a concentration of $c$-axes normal to bedding proposed by Carlson and Christensen (1979) is present but not pronounced.

The crystallite orientation distribution function was used in conjunction with the elastic stiffness coefficients 


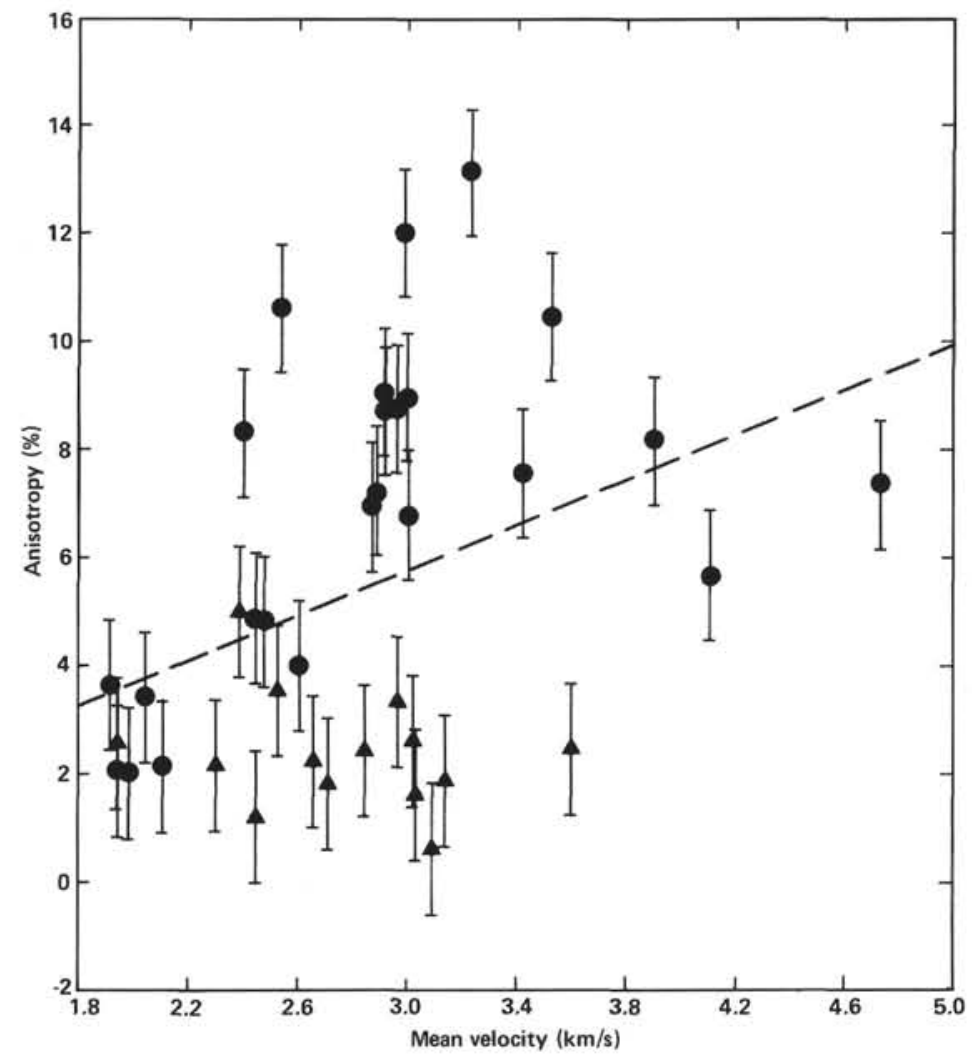

Figure 4. Anisotropy versus mean velocity showing poor correlation; $r=0.38$. Circles and triangles indicate bedded and unbedded samples, respectively.

for calcite published by Dandekar (1968) to calculate the stiffness coefficients for a nonporous aggregate by methods described by Crosson and Lin (1971) and Baker and Carter (1972). Horizontal and vertical velocities were then calculated from the average stiffnesses, and the degree of anisotropy of a nonporous aggregate of pure calcite with the fabric shown in Figure 6 (i.e., a slight concentration of $c$-axes normal to bedding) was less than $1 \%$. The magnitude of the calculated anisotropy of an appropriately porous aggregate would be significantly lower. Thus, although compaction and diagenesis do appear to produce concentrations of calcite $c$-axes normal to bedding, this fabric is not sufficiently strong to contribute appreciably to the acoustic anisotropy of calcareous deep-sea sediments.

A remaining potential cause of acoustic anisotropy in deep-sea sediments is bedding. A medium consisting of alternating layers with different elastic properties can be anisotropic if the acoustic wavelength is long compared to the thickness of the layers (Postma, 1955; Backus, 1962). Larson, Moberly, and others (1975) suggested that alternating thin layers of carbonate and chert or clay might cause acoustic anisotropy in deep-sea sediments, but they presented no evidence to support this hypothesis. Two lines of evidence from our data set suggest that they are correct.

First, compositional layering cannot occur in a singlecomponent system; at least one mineral constituent other than calcite must be present. As shown in Figure 7, there is a marked negative correlation $(r=-0.74)$ between velocity anisotropy and carbonate content. This relationship suggests that the introduction of noncarbonate components is related to the phenomenon of acoustic anisotropy.

The second, and much stronger, line of evidence that supports bedding as the cause of elastic anisotropy in deep-sea sediments is shown in the 14 of the 40 samples included in this study that have little visible evidence of bedding. Figure 8 illustrates the relationship between anisotropy and depth for all samples. The well-bedded samples have anisotropies ranging from 2 to $13 \%$, and anisotropy is strongly correlated with depth $(r=0.84)$. By contrast, anisotropy in the unbedded samples is generally less than $4 \%$ and is unrelated to depth. We have attempted to relate anisotropy in bedded samples to depth and carbonate content by multiple linear regression. The resulting relation is

$$
\begin{aligned}
\mathrm{A}=6.9( & \pm 2.9)+7.0( \pm 1.4) \mathrm{z}-9.5( \pm 3.0) \mathrm{c} ; \mathrm{r}=0.89, \\
\text { where } \mathrm{A} & =\text { anisotropy (in \%) } \\
\mathrm{z} & =\text { depth (in } \mathrm{km}) \\
\mathrm{c} & =\text { carbonate content (in \%) }
\end{aligned}
$$

A plot of calculated versus observed values is shown in Figure 9. This empirical relation for bedded sediments consistently overestimates the degree of anisotropy when applied to samples that show little evidence of bedding. In view of the fact that anisotropy is so strongly cor- 


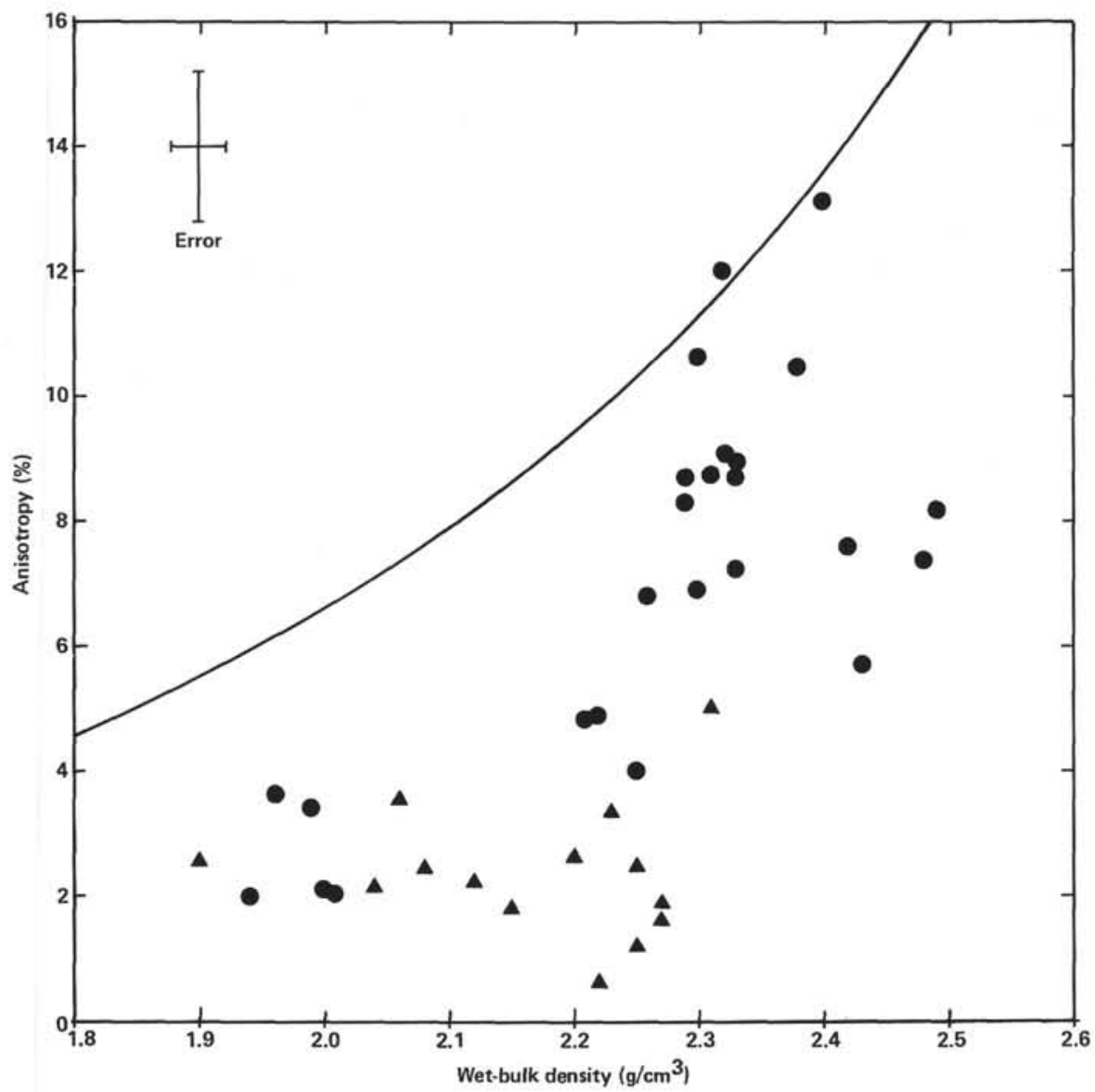

Figure 5. Anisotropy versus wet-bulk density in visibly bedded (circles) and unbedded (triangles) sediment samples. The solid line shows the approximate relationship between anisotropy and density in a porous single crystal of calcite.

related with bedding, we conclude that compositional variations related to bedding are the principal cause of acoustic anisotropy in indurated, calcareous, deep-sea sediments.

\section{CONCLUSION}

The principal conclusions of this study are:

1) Velocity anisotropy is not as strongly correlated with density or mean velocity as previously thought.

2) Calcareous, deep-sea sediments may be regarded as transversely isotropic media with a symmetry axis normal to bedding.

3) There is a preferred orientation of calcite in these sediments, with the maximum concentration of $c$-axes perpendicular to bedding, but this fabric does not contribute appreciably to elastic anisotropy.

4) The degree of velocity anisotropy shows a strong, negative correlation with carbonate content, and visibly bedded sediments are markedly more anisotropic than those that are not well bedded. The principal cause of velocity anisotropy appears to be bedding, but preferred orientation of clay minerals has not been ruled out as a potential contributor to anisotropy of bedded samples. The increase of anisotropy with depth in the case of bedded samples suggests that the contrast between layers is enhanced by compaction and diagenesis.

\section{ACKNOWLEDGMENTS}

S. Gebhard assisted in making the laboratory measurements of physical properties. R. Rezak's facilities were used to measure carbonate contents. We particularly wish to thank N. I. Christensen for the use of his high-pressure laboratory and J. Schultz for his assistance in developing the urethane sample holder. This research was supported by National Science Foundation Grant OCN 7817919 and Office of Naval Research Contract N-00014-80-C-0013. This is Texas A\&M Geodynamics Research Program Contribution No. 26.

\section{REFERENCES}

Bachman, R. T., 1979. Acoustic anisotropy in marine sediments and sedimentary rocks. J. Geophys. Res., 84:7661-7663.

Backus, G. E., 1962. Long-wave elastic anisotropy produced by horizontal layering. J. Geophys. Res., 67:4427-4440.

Baker, B. W., and Carter, N. L., 1972. Seismic velocity anisotropy calculated for ultramafic minerals and aggregates. In Heard, H. C., Borg, I. V., Carter, N. L., and Raleigh, C. B. (Eds.), Flow and Fracture of Rocks: Washington (Am. Geophys. Union), Geophysical Monograph, 16:157-166.

Bevington, P. R., 1969. Data Reduction and Error Analysis for the Physical Sciences: New York (McGraw-Hill Book Co.).

Boyce, R. E., 1976. Sound velocity-density parameters of sediment and rock from DSDP Sites $\mathbf{3 1 5}-318$ on the Line Islands Chain; Manihiki Plateau, and Tuamotu Ridge in the Pacific Ocean. In Schlanger, S. O., Jackson, E. D., et al., Init. Repts. DSDP, 33: Washington (U.S. Govt. Printing Office), 695-728.

Carlson, R. L., 1981. Acoustic properties of limestones from the northcentral Pacific, Deep Sea Drilling Project Leg 62. In Thiede, J., Vallier, T. L., et al., Init. Repts. DSDP, 62: Washington (U.S. Govt. Printing Office), 999-1004. 
1982. Acoustic properties of tuffaceous and calcareous sediments, Deep Sea Drilling Project Leg 60. In Hussong, D. M., Uyeda, S., et al., Init, Repts. DSDP, 60: Washington (U.S. Govt. Printing Office), 803-804.

Carlson, R. L., and Christensen, N. I., 1979. Velocity anisotropy in semi-indurated calcareous deep-sea sediments. J. Geophys. Res., 84:205-211.

Carlson, R. L., Christensen, N. I., and Wilkens, R. H., 1981. Acoustic properties of volcaniclastic sediments recovered from the floor of the Philippine Sea, Deep Sea Drilling Project Leg 59. In Kroenke, L., Scott, R., et al. Init. Repts. DSDP, 59: Washington (U.S. Govt. Printing Office), 519-522.

Crosson, R. S., and Lin, J., 1971. Voigt and Reuss prediction of anisotropic elasticity of dunite. J. Geophys. Res., 76:570-578.

Dandekar, D. P., 1968. Elastic constants of calcite. J. Appl. Phys., 39:2971-2973.

Hamilton, E. L., 1978. Sound velocity-density relations in sea-floor sediments and rocks. J. Acoust. Soc. Am., 63:366-377.

, 1980. Geoacoustic modeling of the sea floor. J. Acoust. Soc. Am., 68:1313-1340.

Kim, D. C., Katahara, K. W., Manghnani, M. H., and Schlanger, S. O., 1982. Velocity and attenuation anisotropy in deep-sea carbonate sediments. EOS Trans. Am. Geophys. Union, 63:434.
Larson, R. L., Moberly, R., et al., 1975. Init. Repts. DSDP, 32: Washington (U.S. Govt. Printing Office).

Milholland, P., Manghnani, M. H., Schlanger, S. O., and Sutton, G. H., 1980. Geoacoustic modeling of deep-sea carbonate sediments. J. Acoust. Soc. Am., 68:1351-1360.

Postma, G. W., 1955. Wave propagation in a stratified medium. Geophysics, 20:780-806.

Roe, R. J., and Krigbaum, W. R., 1964. Description of crystallite orientation in polycrystalline materials having fiber texture. J. Chem. Phys., 40:2608-2615.

Tucholke, B. E., Edgar, N. T., and Boyce, R. E., 1976. Physical properties of sediments and correlations with acoustic stratigraphy: Leg 35, Deep Sea Drilling Project. In Hollister, C. D., Craddock, C., et al., Init. Repts. DSDP, 35: Washington (U.S. Govt. Printing Office), 229-250.

Wyllie, M. R. J., Gregory, A. R., and Gardner, G. H. F., 1958. An experimental investigation of factors affecting elastic wave velocities in porous media. Geophysics, 23:459-493.

Wyllie, M. R. J., Gregory, A. R., and Gardner, L. W., 1956. Elastic wave velocities in heterogeneous and porous media. Geophysics, 21:41-70.

Date of Initial Receipt: July 15, 1982 

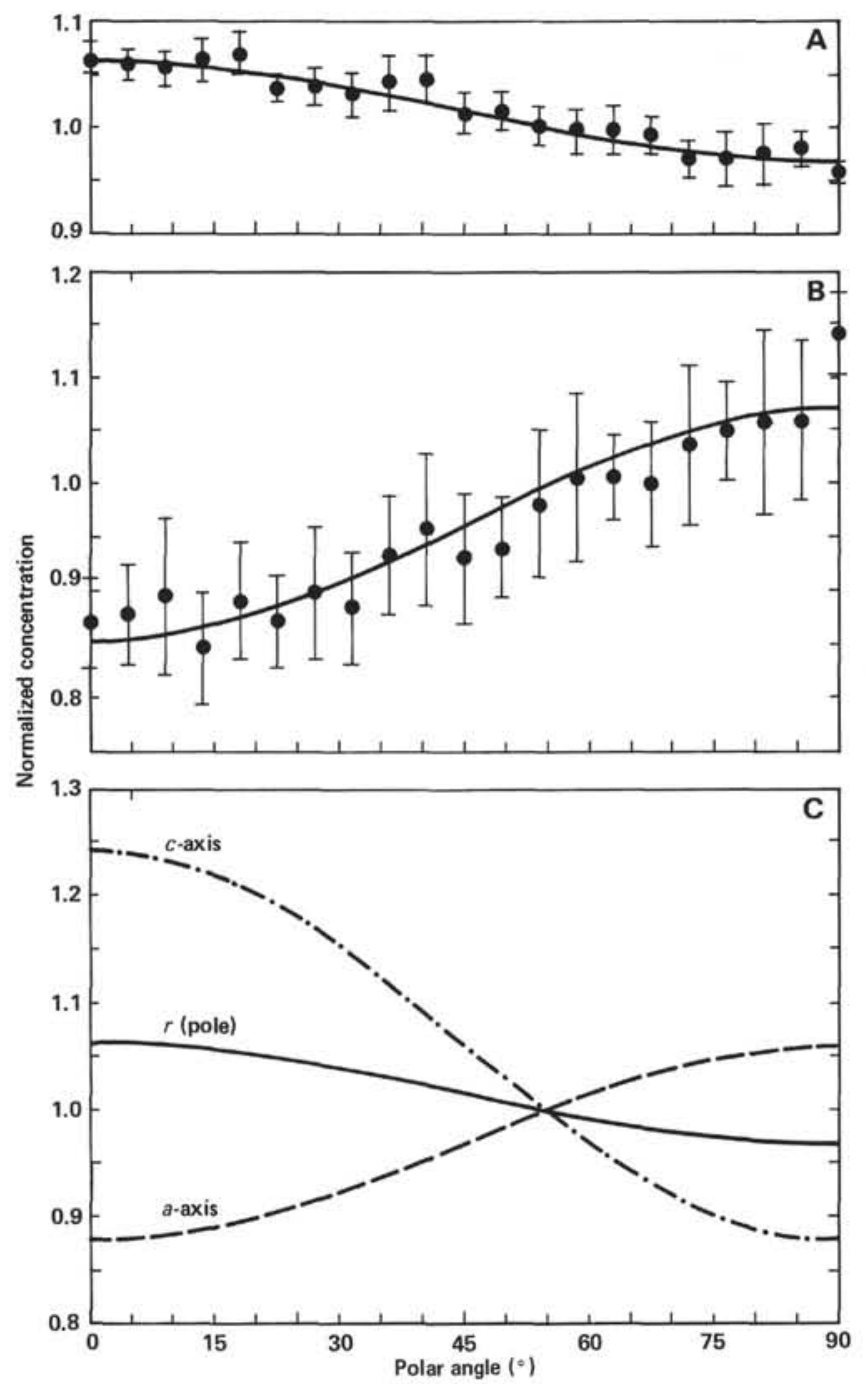

Figure 6. Typical result of X-ray analysis of grain orientation (Sample $516 \mathrm{~F}-86-2,44-54 \mathrm{~cm}$ ). In both $\mathrm{A}$ and $\mathrm{B}$, the discrete data points and associated error bars represent the means and standard deviations from 12 equivalent $0-90^{\circ}$ intensity profiles, and the solid line is the best-fitting second-order Legendre Polynomial series found by a least squares method (Bevington, 1969). A: normalized X-ray intensity distribution for the calcite $r$-plane normal. B: normalized $\mathrm{X}$-ray intensity distribution for the calcite $a$-axis. C: diffracting plane distribution functions, including the estimated $c$-axis distribution. Calcite $c$-axes are weakly concentrated normal to bedding. 


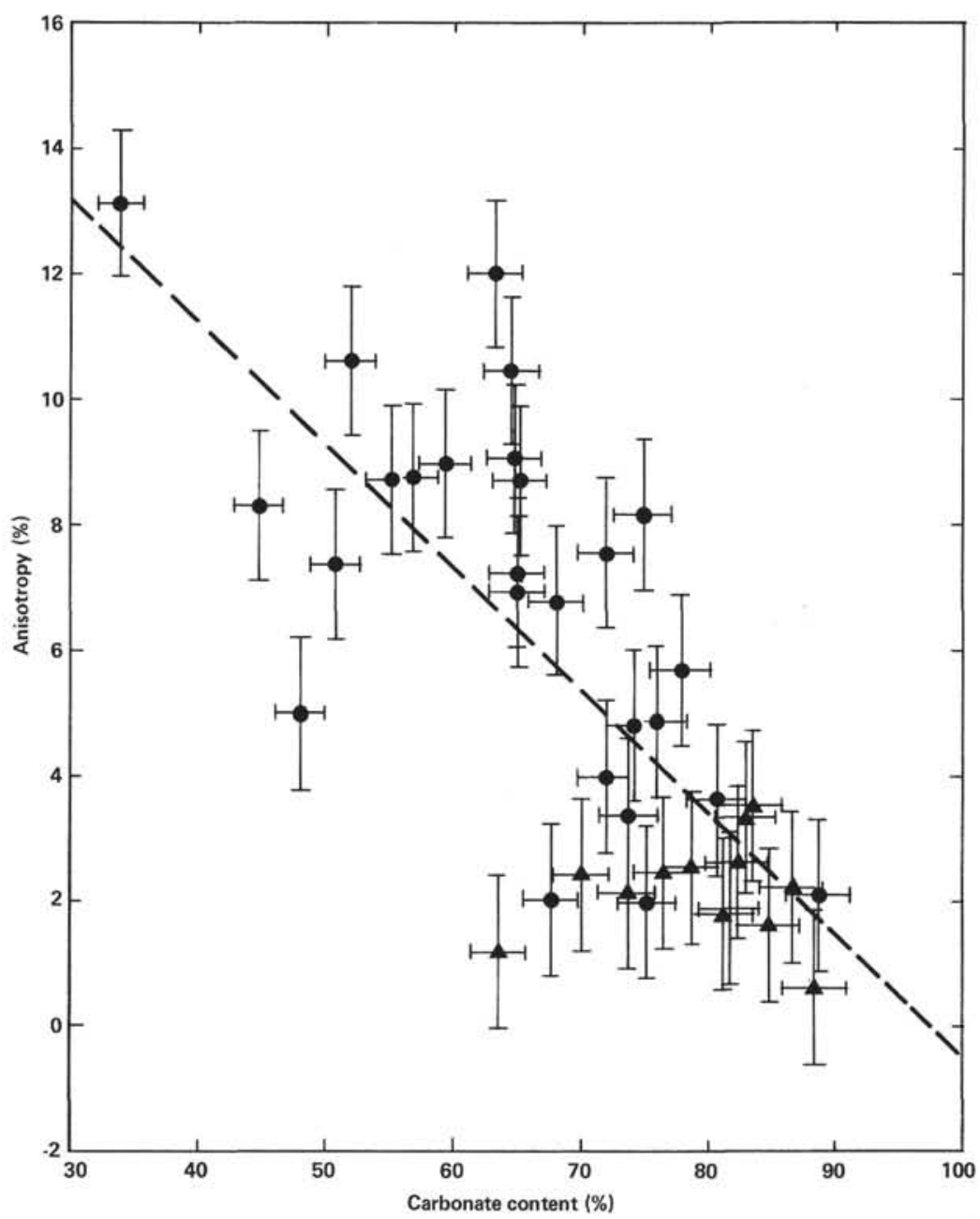

Figure 7. Anisotropy versus carbonate content. Circles and triangles indicate bedded and unbedded samples, respectively. 


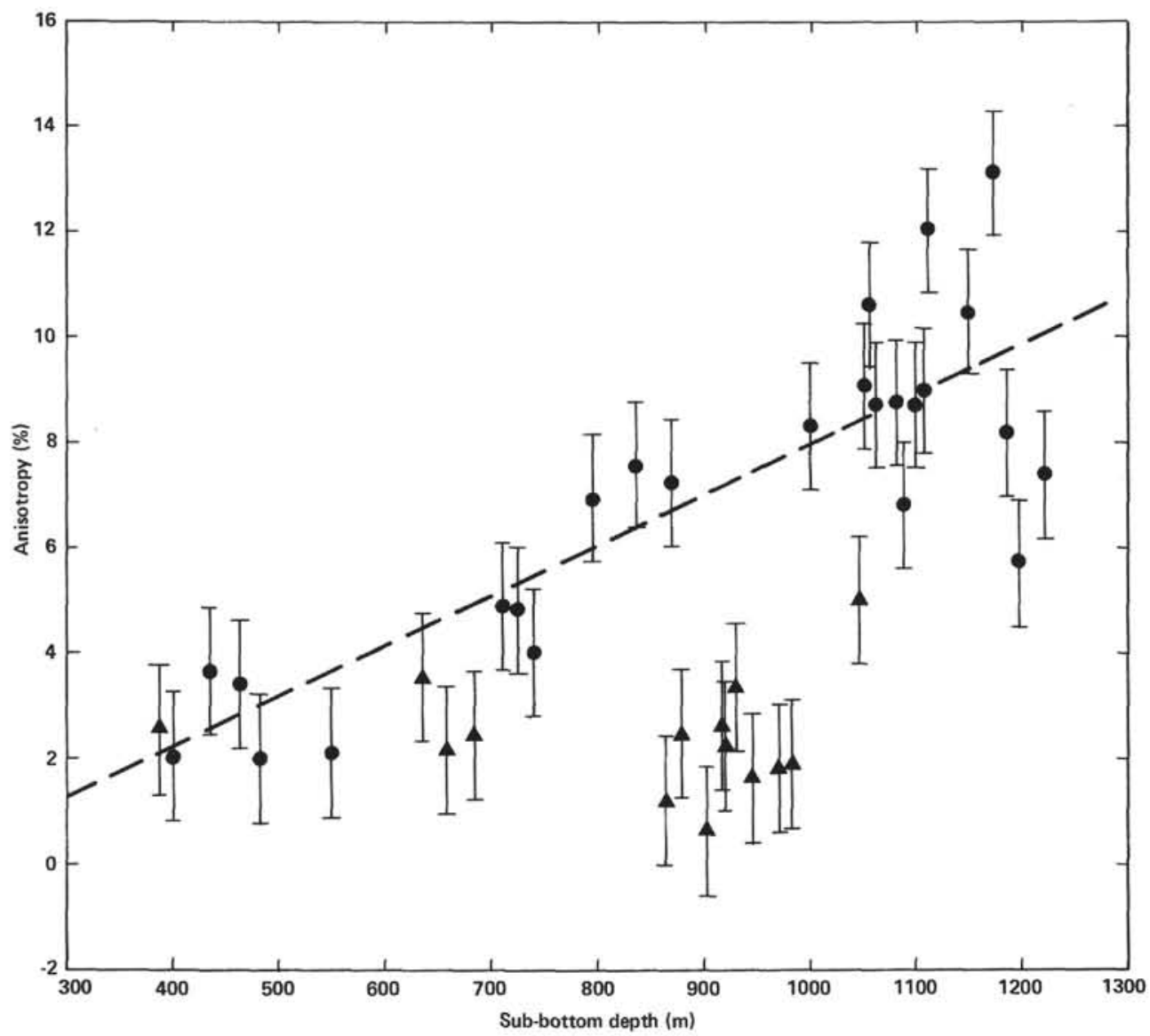

Figure 8. Anisotropy versus depth of recovery. Circles and triangles indicate bedded and unbedded samples, respectively. 
R. L. CARLSON, C. H. SCHAFTENAAR, R. P. MOORE

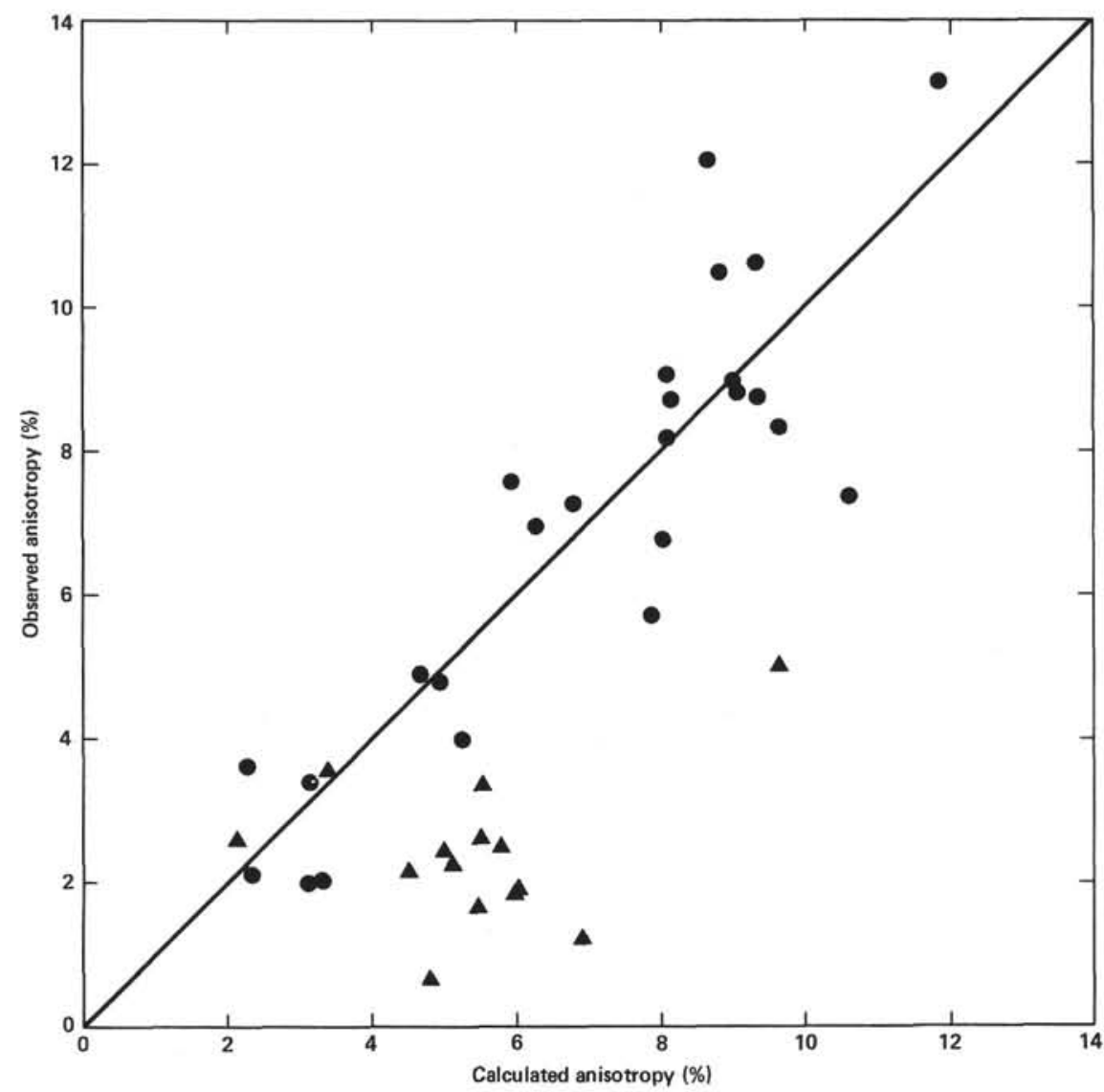

Figure 9. Observed anisotropy versus anisotropy calculated from carbonate content and depth of bedded samples according to a linear relation obtained by multiple linear regression. Circles and triangles indicate bedded and unbedded samples, respectively. 